\title{
COVID-19 and Learning Styles: GCET as Case Study
}

\author{
Mazhar Hussain Malik ${ }^{1, *}$, Amjed Sid Ahmed ${ }^{1}$ and Sulaiman Al Hasani ${ }^{2}$ \\ ${ }^{1}$ Department of Computing and Information Technology, Global College of Engineering and Technology, \\ Muscat, Sultanate of Oman \\ ${ }^{2}$ Department of Electrical and Electronics Engineering, Global College of Engineering and Technology, \\ Muscat, Sultanate of Oman \\ *Corresponding Author: Mazhar Hussain Malik. Email: mazhar@gcet.edu.om \\ Received: 28 September 2020; Accepted: 18 December 2020
}

\begin{abstract}
The COVID-19 pandemic has caused higher educational institutions around the world to close campus-based activities and move to online delivery. The aim of this paper is to present the case of Global College of Engineering and Technology (GCET) and how its practices including teaching, students/staff support, assessments, and exam policies were affected. The paper investigates the mediating role of no detriment policy impact on students' result along with the challenges faced by the higher educational institution, recommendations and suggestions. The investigation concludes that the strategies adopted for online delivery, student support, assessments and exam policies have helped students to effectively cope with the teaching and learning challenges posed by the COVID-19 pandemic without affecting their academic results. The study shows that $99 \%$ of students were able to maintain the same or better level of performance during the 1st COVID-19 semester. One percent of students had shown a slight decrease in their performance (about 1\%-2\%) with respect to their overall marks pre-COVID-19. The no detriment policy has succoured those $1 \%$ of the students to maintain their overall performance to what it used to be pre-COVID-19 pandemic. Finally, the paper provides the list of challenges and suggestions for smooth conduction of online education.
\end{abstract}

Keywords: Higher education; learning styles; COVID-19 challenges and strategies; no detriment policy; engineering and technology modules

\section{Introduction}

\subsection{Learning Process, Teaching and Learning Styles}

The process of learning is essential to human beings. It improves their ethos and understanding of the environment around them. Furthermore, it enhances the cognitive and the social skills of a person, giving access to their cultural heritage, that has accrued through the history of humanity. Still, through the creation of new knowledge, education advances the cultural heritage of an individual. With recent debates on the issues surrounding lifelong learning, an interest in formal adult education has increased [1]. Also, there is an emergence of interest in issues that

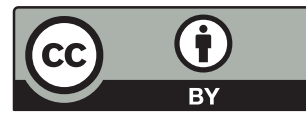

This work is licensed under a Creative Commons Attribution 4.0 International License, which permits unrestricted use, distribution, and reproduction in any medium, provided the original work is properly cited. 
enhance the learning capability of the aged people. Still, it is acceptable for people to use diverse learning methods and a preference for stimuli that can facilitate the process of learning. In this regard, when some learners prefer to use written text, debates and readings, others would choose diagrams, videos and images. In the view of [2], the previous four decades witnessed an increase in the study of many learning styles. Reference [3] managed to identify about 70 theories of learning, that emerged during the last three decades. These theoretical frameworks, corresponded to the questionnaires, that were used by the industry to determine the learning styles of students, and the relationships they had with teachers and fellow learners. This is either through virtual or physical methods [4]. One of the widely known theoretical frameworks is the Dunn Learning Styles Model. Another important theory for learning is called the Kolb's Learning Styles Inventory. Finally, the Learning Styles Questionnaire by Honey and Mumford is used to explain the educational approaches of learners.

The notion of the learning style of a student refers to how they process and retain information during the process of receiving knowledge. Even so, when it comes to a learner model, its most essential component is the domain-independent data, and the description of the cognitive characteristic [5]. Other elements include psychosocial behaviours that act as stable indicators of how learners can perceive, respond and interact with their learning surrounding [6]. In the view of Kolb and Kolb, learning style refers to, "the determination of the differences of an individual method of learning based on their preference to using the various phases of the educational cycle [6]. Indeed, the styles of learning identify the behaviour of a learner as characteristics like convergence and divergence. Divergent students are emotional and creative. On the other hand, convergent learners use logic to come up with a solution to a problem. On a general perspective, students have more than one learning style [7,8]. These methods of learning correspond to the various characteristics that define them. But researchers identified four patterns that correspond to the aggregation of a particular learning style of a student. They called these patterns, "learning style models." These models comprise of many aspects that describe the way learners distinguish and process information [9]. In this regard, different models of educational styles used various theories to define and categorize a particular method of learning.

\subsection{COVID-19 and Infulunce on Delivery}

The World Health Organization (WHO) declared the COVID-19 as a pandemic on the 12th of March 2020. The COVID-19 pandemic has impaired the educational, socio-cultural, and economic systems around the world [10]. As this overwhelming pandemic is still on, it is difficult to determine its long-term impact. Although, the world has experienced several pandemics in the past, their long term effects on the behaviour, economy, and society have not been studied [11] Thus, making the long-term effects of this pandemic hard to predict.

In the United Kingdom, the COVID-19 has led to a devastating impact. For instance, UK universities have lost about $£ 790$ million. This is because the higher learning institutions are unable to make revenues from the accommodation, conferencing, and catering services. The same predicament also faces higher learning institutions in the United States. For instance, in 2017, higher learning institutions made about the US $\$ 44.6$ billion in the United States. This money was earned from the halls of residence, bookstores, and the summer camps. In the current year, the higher learning institutions are likely to make lower revenue figures, which is about $\$ 30$ billion. Also, the higher learning institutions in Australia do not expect to make any gains in revenue. They are expecting to lose about AUS \$3-4.6 billion. In this regard, universities are expected to 
roll out online teaching programs. This would entail the emergence of unexpected expenditures, which would affect their incomes.

These institutions will have to find resources to pay their staff, fund research programs, and carry out deep-cleaning initiatives. Moreover, in the coming year, the losses that higher learning institutions would make will be significant. The economic recession will not allow thousands of students to enrol in higher education. For instance, the economic downturn is better depicted by the fact that in April 2020, about 20 million people lost their jobs in the United States. On the other hand, in the United Kingdom, higher education institutions may lose revenue from students outside the EU. These learners usually contribute an annual fee of about $£ 6.9$ billion. Indeed, this is a large amount of money that makes about a third of the income generated by higher education institutions. In this regard, if the global student market collapses, there would be severe consequences in the educational sector of the United Kingdom and the United States [12].

\section{Related Work}

Many countries in the world are embracing the use of digital technology to facilitate the teaching process. Teachers, students, and educational stakeholders use digital technology to improve the learner's experience and enhance the administrative process. The use of digital technology as a tool for the learning process is because of its flexibility and capability to improve a student's teaching and learning experience. Similarly, digital technology helps to enhance the personalization of the learning process and enhances the ability of learners to access the learning resources while they are off campus. It is inevitable that for students to succeed in using digital technology, they need to acquire new skills and knowledge and embrace the changes in the learning process [13].

Researcher [14,15] mentioned that distance learning involves providing instructions through a non-traditional method such as online, television, correspondence and radio. There are two types of distance learning sessions synchronous and asynchronous sessions. On a synchronous session, the process of learning occurs in real-time, students participate and interact during the session with the instructor and with their peers. On the other hand, asynchronous learning does not entail the simultaneous participation of the students and instructors. In the asynchronous session, there is no need to gather students at the same time to engage in the process of learning, students can view the pre-recorded materials on their own time [16]. There is a strong trend in higher education institutions to use digital technology to support students' education. Universities have managed to introduce the so called Massive Open Online Courses (MOOCs), e-learning management system, and blended long-distance courses [17].

Lecture capturing is one of the methods used to support blended learning. Aimed at recording online teaching sessions and making them available to students, lecture capturing is regarded as a mean to help students who are not able to attend live classes [18]. In recent years, preCOVID-19 pandemic, there was a surge in online learning and teaching. For instance, the United States has experienced about 3.2 million complete online enrolments during fall term of 2005 [19]. In this regard, experts need to carry out a study on the impact of online classes on the academic and social well-being of students [20]. In the view of [21], the classroom environment helps to bridge the academic and social integration of higher education students. Also, the relationship that occurs in online classes is of great importance to students. Tinto goes on to denote that the activities of teachers within the classroom environment play a role in enhancing their notion of scholarly belonging. 
Furthermore, it enhances the ability of students to persist while engaged in their academic pursuits. Besides, there is research evidence supporting the fact that the development of an online community has a positive impact on the overall success of a student in the education sector [21]. But, there are still questions about a fully online class's ability to support and enhance the growth of a high level of learning communities [22,23]. From a general perspective, online education makes it possible for students to interact with their teachers and their classmates compared to traditional teaching methods actively. Moreover, when students are anonymous, they can actively question their instructors without fear. On the contrary, online education has several challenges, which are identified by [24,25], and their summary is contained in the Tab. 1.

Table 1: Online education challenges

\begin{tabular}{|c|c|c|}
\hline Student challenges & Teacher challenges & Institutions challenges \\
\hline $\begin{array}{l}\text { Self-regulation } \\
\text { challenges. } \\
\text { Technological literacy } \\
\text { and competency } \\
\text { challenges. } \\
\text { Students isolation } \\
\text { challenges. } \\
\text { Technological sufficiency } \\
\text { challenges. } \\
\text { Technological } \\
\text { complexity challenges. }\end{array}$ & $\begin{array}{l}\text { Teachers technological. } \\
\text { literacy and competency } \\
\text { challenges. } \\
\text { Online video challenges. } \\
\text { Technological operation } \\
\text { challenges. } \\
\text { Teachers belief } \\
\text { challenges. }\end{array}$ & $\begin{array}{l}\text { Technological provision } \\
\text { challenges. } \\
\text { Teachers training } \\
\text { challenges. } \\
\text { Lack of technicians. }\end{array}$ \\
\hline
\end{tabular}

\section{No Detriment Policy in Education}

The no detriment policy aims to ensure that a student is not at a disadvantage due to changes in the rules and regulations of the education process. This can be in the form of calculating and evaluating two effects or outcomes.

- The effects of the changes were not initiated.

- The effects after the changes have been implemented.

Under the principle of no detriment policy, formulators will choose an option that is beneficial to students. The possibilities are implemented in a blanket manner and within a specific timeframe. The reason is that it is challenging to implement the policies on a case by case manner. Moreover, for many higher education provider, the doctrine of no detriment would mean that the final grade of a student would be higher than their average performance. For others, it is getting at least a pass in their academic studies despite the pandemic's existence. Even so, some educational providers do not use the notion "no detriment." The reason is that they do not have 
a safety net, also though they have mechanisms aimed at protecting vulnerable students from the disadvantages that occur through online education. Some of these mechanisms may include changing the method of assessments, increasing time for doing exams, and using past academic performances to calculate a student's grade.

Moreover, bodies that award certificates have to enhance the academic standard and ensure the qualifications they award is of an excellent standard. Also, it is their responsibility to protect their students and providers, and ensure their interests are catered for during the global pandemic. Even so, it is not wise to come up with a final classification of student performance, mainly, if he is vulnerable to medical and personal conditions that are beyond the control of the learner [3]. In this regard, no detrimental approaches work at a cohort level, similarly to the approaches that handle extenuating or mitigating situations work at an individual level, and focusing on actual, instead of potential achievement.

Nonetheless, in circumstances where the educators do not have a "no detriment" policy, they have established some exceptions. For instance, it is a challenge to apply the no detriment policy to courses regulated by the professional, statutory, and regulatory bodies (PRSB). In as much as this can look to be complicated, but, significant differences exist between the providers. These differences are on students' population, dates of learning, the structure of the course, and methods of instruction. Other variations are on the assessment methods and the content of the curriculum. Thus, it is essential that when no detriment policy is developed, there is a need to consider the stated differences. In this regard, educational providers have their policies, and it is for learners to attend learning institutions that have policies that better serve their needs.

\section{Research Methodology}

This study is using a descriptive research method by using secondary data which is obtained from Global College of Engineering and Technology student's results both current and previous semesters. This study is investigating the mediating role of no detriment policy on scheduled learning, independent learning and students result. After obtaining the data from a secondary resource, we used Statistical Package for Social Sciences (SPSS) to validate the hypothesis.

A population data set contains all students who are studying at the Global College of Engineering and Technology, while using our sample data which contain a part or a subset of population representing the overall population. A sample of 140 students were used in this study out of the total college's population 1000 students (i.e., sample size 14\%). Tab. 2 shows the size of population, sampling frame and selection of respondents, in this case graduating students.

Table 2: Population, sampling frames and respondents

\begin{tabular}{lll}
\hline Population & Sampling frame & Respondent selection \\
\hline 1000 students & 140 students & Final year project students \\
\hline
\end{tabular}




\subsection{Sample Size}

The size of sample is critical in statistical analysis and according to researcher Luka and Robin (1987) the more complex the analysis the bigger the sample size is required. Using SEM, the sample size of this study consists of 140 participants which contributes to $14 \%$ of the total GCET students. The number of selected students has been classified in the term of selected GCET programmes (where students are graduating) and number of students mentioned in Tab. 3.

Table 3: Number of staff, location, and percentages

\begin{tabular}{lll}
\hline Programme name & Number of participants & Percentage (\%) \\
\hline B.Eng (hons) Electronics and Telecommunication Engineering & 66 & 44 \\
B.Eng (hons) Instrumentation and Control Engineering & 4 & 3 \\
B.Eng (hons) Mechanical and Vehicle technology & 59 & 42 \\
B.Eng (hons) Software Engineering & 11 & 8 \\
Total & 140 & 100 \\
\hline
\end{tabular}

\subsection{Conceptual Framework}

The Overall conceptual work is shown in the Fig. 1. The conceptual work is based on the seven hypotheses. Scheduled learning (SL) and Independent Learning (IL) are two independent variables, No Detriment Policy (NDP) is mediating variable, while Students Performance (SP) is depending on variable. The study is measuring the students performance based on independent variables with mediating affect of No Detriment Policy (NDP) during COVID-19.

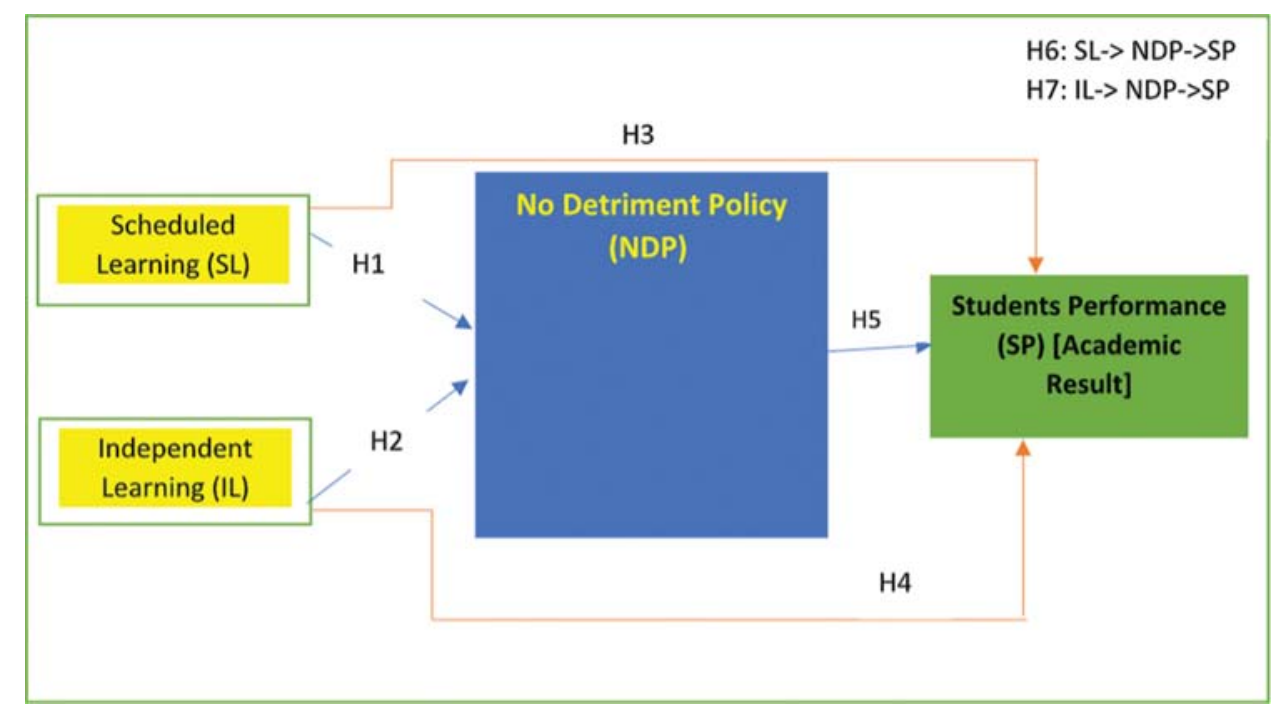

Figure 1: Conceptual framework

\subsection{Research Questions}

- What is the impact of scheduled learning and independent learning on students result?

- What is the impact of scheduled learning and independent learning on no-detriment policy?

- What is the effect of no-detriment policy on students' result? 


\subsection{Research Hypothesis}

The hypothesis is divided into four major parts. The first part is to investigate the relationship between scheduled learning and independent learning no-detriment policy $(\mathrm{H} 1-\mathrm{H} 2)$. The second part is to investigate the relationship between scheduled learning and independent learning on Students result $(\mathrm{H} 3-\mathrm{H} 4)$. The third part will investigate the impact of no-detriment policy on Students result (H5) and finally to understand the mediating role of no-detriment policy on schedule learning and independent learning on students result (H6-H7).

The research is intended to test the following hypotheses:

H1: To investigate the relationship between Scheduled Learning (SL) and no detriment policy (NDP).

H2: To investigate the relationship between Independent Learning (IL) and no detriment policy (NDP).

H3: There is a significant relationship between Scheduled Learning (SL) on Students Result (SR).

H4: There is a significant relationship between Independent Learning (SL) on Students Result (SR).

H5: There is a significant impact of no detriment policy (NDP) on Students Result (SR).

H6: No detriment policy (NDP) mediates the relationship between the Schedule Learning (SL) and Students Result (SR).

H7: No detriment policy (NDP) mediates the relationship between the Independent Learning (IL) and Students Result (SR).

\section{Strategies}

\subsection{Initial Challenges Driving Force for Strategies}

Following the Ministry of Higher Education Oman (MOHE) decision to suspend all campus based activities at all educational institutes in the country as a measure to stop the spread of COVID-19, colleges and universities split between either continuing education online or postpone education until further notice. The global College of engineering and Technology (GCET) management called an urgent meeting of head of department and units to ensure the proper implementation of contingency plan in the light of recent development. It was decided that GCET will move to full online delivery and lectures recording will be available as per usual practice to support students learning during this suspension.

\subsection{Learning Type and GCET Strategies}

GCET provided online education during this pandemic and all the classes were conducted without any interruption using an online learning platform blackboard. All the classes were conducted the same as actual scheduled lecture time and students could attend the classes online. The GCET provided necessary infrastructure to support staff members for the smooth delivery of the module so that they can deliver lectures from home without any interruption. A mixture of synchronous and asynchronous delivery were used.

\subsection{Online Platforms}

GCET is using Blackboard Learning Management System LMS platform which enabled the use of the so called "Blackboard Collaborate Ultra" a service to enable online live session and 
contains many features such as pooling, group discussion, group meeting...etc. All classes were conducted online with class size of maximum 30 students and students had the opportunity to have access to lecture recording after the class using their BB LMS account.

\subsection{Group Work}

Considering the fact that students need to work in Group the module team was giving Blackboard collaborate ultra-dedicated link to each group which they were using to conduct the group meeting and to work in a group consider that facts that social media applications are banned in the country along with suggestion to use options such as Google meeting and hang out.

\subsection{Recording Presentation}

To address the issue of recording individual or group presentation, students were giving the choice of using Blackboard collaborate ultra as presenter access which allow them to record the presentation and recording will directly save to $\mathrm{BB}$ which was accessed by the module team; also Kaltura capture was which help user to record the video media using a combination of webcam, audio, screen recording and presentation file. Kaltura is suitable for individual presentation and Blackboard collaborate ultra-enable students to present work in a group.

\subsection{Assessments Methods}

Considering the fact that all the assessments need to conduct online, the head of Department conducted meetings with module leaders to make the necessary changes in the assessments so assessments can be suitable for $24 \mathrm{~h}$ take home exam which was conducted using blackboard.

Examination Department announce the final exam dates and the head of Department along with program leaders were making sure that that the assessments are available on Blackboard for a specific time interval which was set from 10:00 AM to 10:00 AM (24 H) and the student had opportunity to download the exam paper and solve within defined time interval and then upload to Blackboard wire submission link.

\subsection{No Detriment Approach}

Consider this uncertain situation of a pandemic which was new for all of us and UWE and GCET were trying to ease the stress and concerns of staff and students as much as can be. GCET adopted UWE, Bristol no detriment approach to the 19/20 academic year which means that as long as a student qualifies to progress or graduate based on the marks obtained this academic year then we will ensure that their final academic year average is the same as, or higher than, the average they attained up to Wednesday 18 March 2020.

\section{Results Analysis}

The Tab. 4 shows the hypothesized construct direct effects which support H1, H2, H3, H4 and rejects H5. The study outcomes show that No detriment Policy does not have direct impact on student results in this case study. The study evidence that necessary actions and measures were taken to support students during the COVID-19 which help students to maintain their academic performance.

Tab. 5 shows the students result by considering mediating role and outcomes verify the mediating role of no detriment policy as per $\mathrm{H} 6$ and $\mathrm{H} 7$. 
Table 4: Examining hypothesized construct direct effects

\begin{tabular}{|c|c|c|c|c|c|c|}
\hline \multirow[t]{2}{*}{ Path } & \multicolumn{2}{|c|}{ Unstandardized estimate } & \multirow{2}{*}{$\frac{\text { Standardized estimate }}{\text { Beta }}$} & \multirow[t]{2}{*}{ Critical ration (c.r.) } & \multirow[t]{2}{*}{ P-value } & \multirow[t]{2}{*}{ Hypothesis result } \\
\hline & Estimate & S.E. & & & & \\
\hline $\mathrm{SL} \rightarrow \mathrm{SR}$ & 0.186 & 0.059 & $0.191^{* *}$ & 3.221 & 0.003 & H3) Supported \\
\hline $\mathrm{IL} \rightarrow \mathrm{SR}$ & 0.197 & 0.063 & $0.223^{* *}$ & 3.684 & 0.002 & H4) Supported \\
\hline $\mathrm{SL} \rightarrow \mathrm{NDP}$ & 0.187 & 0.079 & $0.150^{*}$ & 2.869 & 0.03 & H1) Supported \\
\hline $\mathrm{IL} \rightarrow \mathrm{NDP}$ & 0.185 & 0.077 & $0.161^{*}$ & 2.919 & 0.03 & H2) Supported \\
\hline $\mathrm{NDP} \rightarrow \mathrm{SR}$ & 0.141 & 0.051 & 0.112 & 1.223 & 0.099 & H5) Rejected \\
\hline
\end{tabular}

Table 5: Students result by considering mediating role scheduled learning (SL)

\begin{tabular}{|c|c|c|}
\hline \multicolumn{3}{|c|}{ Independent variables (IVs) } \\
\hline $\begin{array}{l}\mathrm{DV}=\text { Students result }(\mathrm{SR}) \\
\mathrm{M}=\text { No-detriment policy (NDP) }\end{array}$ & Scheduled learning (SL) & Independent learning (IL) \\
\hline Total effect of IV on DV without M & $0.156^{*(s i g: 0.013)}$ & $0.228^{* *(s i g: 0.002)}$ \\
\hline Direct effect of IV on DV with $\mathrm{M}$ & $0.117^{(\text {sig:0.065) }}$ & $0.213^{* *(s i g: 0.007)}$ \\
\hline Indirect effect of IV on DV through $\mathrm{M}$ & $0.038^{* *(s i g: 0.005)}$ & $0.031^{* *(s i g: 0.002)}$ \\
\hline Effect of IV on $\mathrm{M}$ & $0.200^{* *(s i g: 0.009)}$ & $0.210^{* *(\text { sig:0.001) }}$ \\
\hline Effect of $\mathrm{M}$ on $\mathrm{DV}$ & $0.192^{* *(s i g: 0.003)}$ & $0.195^{* *(s i g: 0.003)}$ \\
\hline Mediation path & $\mathrm{SL} \rightarrow \mathrm{NDP} \rightarrow \mathrm{SR}$ & $\mathrm{IL} \rightarrow \mathrm{NDP} \rightarrow \mathrm{SR}$ \\
\hline Mediation effect & Yes & Yes \\
\hline Degree of mediation & Full & Partial \\
\hline Hypothesis result & H6) Supported & H7) Supported \\
\hline Direct effect of IV on DV with M & $0.117^{(\text {sig: }: 0.065)}$ & $0.213^{* *(\text { sig:0.007) }}$ \\
\hline Indirect effect of IV on DV through $\mathrm{M}$ & $0.038^{* *(s i g: 0.005)}$ & $0.031^{* *(s i g: 0.002)}$ \\
\hline Effect of IV on $\mathrm{M}$ & $0.200^{* *(s i g: 0.009)}$ & $0.210^{* *(s i g: 0.001)}$ \\
\hline
\end{tabular}

“* $\mathrm{p}<0.05,{ }^{* *} \mathrm{p}<0.01,{ }^{* * *} \mathrm{p}<0.001 *$

\section{Challenges and Suggestions}

Due to COVID-19 there are a lot of challenges associated with learning and teaching, starting from conduction of classes to special focus to lab work as students have lack of access to lab resources, so it is very important to understand the latest tools and techniques which can be used to conduct virtual labs. Secondly it is very important to provide different types of lecture recording tools to enable different types of recording such as pre-recorded lectures, live recording, and the availability of live recording sessions. This part of the research paper is investigating the challenges related to online learning and teaching along with suggestions which can help to overcome these challenges. 


\subsection{Conducting Lab Work}

The first and foremost challenge of online teaching is the conduction of lab work as students are not able to access campus-based labs. Here are some suggestions and which can help the proceed with remote lab classes.

- Identify the labs that can be taught asynchronously or through video conferencing software's like zoom, Google meeting, net meeting or any learning management platforms such as Moodle or blackboard. It is very important to make sure and explore the option of recording videos to demonstrate lab techniques to your students and it is suggested that Lecture lectures recordings should be available online after the live sessions.

- Pre/post lab work and discussions are a very important part and different online forums can be used to make lab sessions interactive such as all the video conferencing software or learning management platforms enable do have student teacher interaction, along with inter student interaction.

- The higher educational institutions should investigate the possibility of using virtual labs for different lab activities which can help them accomplish some learning goals. Biointeractive, MERLOT simulation Collection, OnlineLabSci and Phet Interactive Simulations are free platforms which can help to deliver online lab sessions. eScienceLabs, Hands-On Lab and SimBio are paid software's which can help to deliver virtual labs related to engineering and technology education.

\subsection{Programming Modules}

Computer programming is an integral part of most of the engineering and technology branches. It is very important that students should be able to practice programming online and there are different tools available which can help to conduct different types of programming language lab sessions in an online environment.

As online compilers can be a useful tool to quickly compile a piece of code without installing a proper compiler on your computer and this is very useful to play with the newest language features and to share code or to compare different compilers considering the fact that you don't need to install anything on your computer. Everything starting from writing the code till output can be done online. TL:DR, The Compliers, Codiva.io, paiza.IO, Wandbox, Godbolt, Coliru, Quick-Bench, Cppinsights, Rextester, Ideone, C++ Shell, Repl.it, TIO-Try it Online, Codechef, JDoodle and Codepad, can be used to write the $\mathrm{C} / \mathrm{C}++$ code. To do web development, Codepen.io, JSFiiddle, JSBin, Koding, Rendera, CodeEnvy, Liveweave, CodeAnywhere, SourceLair and Cloud9 can be used and for Java, Codiva, JDoodle, Rextester, Online GDB, Browxy and IDEOne can be used.

\subsection{Learning Management Platforms}

It is very important for all higher educational institutions to use learning management platforms which are customized to fulfill the needs of higher educational institutions. Blackboard and Moodle are two famous learning management platforms which contribute to $60 \%$ of total learning management platform usage throughout the world. while Blackboard is the leading platform which captures $34 \%$ of market share and it's enabled to provide the interactive learning environment to bridge the gap between students and teachers; it is the best suitable platform for online teaching. Blackboard uses collaborative Ultra which helps to deliver live sessions with the option to download the live sessions at the end of the session Which can be available to students for

unlimited periods. Panopto is another famous video recording and live session conduction tool 
which is used by many higher educational institutions along with Camtasia. Google classrooms can also help to deliver online sessions, while Zoom, Google Meeting, Net meeting are some free of cost platforms which can help to conduct online sessions, but they are not designed for learning environments.

\subsection{Students Demonstration Tools}

Student coursework demonstration is another challenge in online learning and teaching. Due to COVID-19 students are expected to submit a video demonstration of their individual or group work which is the main challenge of how they can record their presentation.

There are different types of options available for individual presentations Such as using video recorders provided by windows which will help them to record their screen and voice, using Microsoft PowerPoint voice narration option. Blackboard supports Kaltura, which is a very useful platform for video recording. The tools which are available through their learning management system such as Camtasia, Panopto and Blackboard collaborate ultra which can help to perform group work recording.

\subsection{Online Interaction Building tools}

As the classes are conducted online it is very important that the session should be interactive and students should be able to ask questions during the session and they should be able to participate actively throughout the conduction of Session. There are different tools which can help to build online interaction between teachers and students to make a session as an interactive session, these tools are Mentimeter, Slido, Kahoot, Ahaslides, Peardeck, nearpod, Pigeonhole, Polleverywhere and wooclap.

\subsection{Connection Issues/Hardware Issues}

Connection and hardware issues are another two major challenges which need to be addressed with high priority for smooth delivery of online education. It is seen that about $10 \%$ students are facing slow Internet issues which need a nationwide policy to provide broadband throughout the country and also it is very important to design the applications in a way that they can run on Low speed Internet.

\subsection{Group Work Challenges and Communication}

Group work and communication is another very important factor in this student learning experience and due to the lock down, students are facing difficulties in to manage group work and communication. In the case of GCET, where we are using Blackboard as a learning management system which give an option called Blackboard collaborate ultra which helps students to work in a group online and the module teams were providing a dedicated link to each group which help them to conduct group work discussions $24 * 7$. There are some free tools which can help to perform group work such as Zoom, Google meeting, next meeting and TeamViewer.

\section{Conclusion}

This paper looks at the strategies and policies implemented by Global College of Engineering and Technology during the COVID-19 pandemic and their efficacy to support the students. The strategies have enabled students to continue their learning journey during the outbreak of the pandemic. The study validates that the strategies helps students to achieve the same or higher academic performance as compared to previous semester/year, and study validates that no detriment 
policy mediating role was very limited but was affected for those $1 \%$ students who performance during COVID-19 decreased about 1\%-2\%. The paper also highlights the challenges and strategies for online education.

Acknowledgement: The authors would like to acknowledge the support of Global College of Engineering and Technology, Muscat, Oman for their support to enable us to access required data.

Funding Statement: This work is supported by Global College of Engineering and Technology (GCET).

Conflicts of Interest: The authors declare that they have no conflicts of interest to report regarding the present study.

\section{References}

[1] I. Sudria, I. Redhana, I. Kirna and D. Aini, "Effect of kolb's learning styles under inductive guided-inquiry learning on learning outcomes," International Journal of Instruction, vol. 11, no. 1, pp. 89-102, 2018.

[2] S. Cassidy, "Learning styles: An overview of theories, models, and measures," Educational Psychology, vol. 24, no. 4, pp. 419-444, 2004.

[3] F. Coffield, "(pdf) Learning styles and pedagogy in post 16 education: A Think! Evidence," 2004. [Online]. Available: http://evidence.thinkportal.org/handle/123456789/62 [Accessed: 27-Sep-2020].

[4] H. Crogman and M. T. Crogman, "Generated questions learning model (GQLM): Beyond learning styles," Cogent Education, vol. 3, no. 1, pp. 1202460, 2016.

[5] M. A. Alzahrani, "The learning experience of international students in canada: Progressive educational theory and passive learning styles," English Language Teaching, vol. 11, no. 7, pp. 76, 2018.

[6] L. Curry and W. Putnam, "Continuing medical education in maritime canada: The methods physicians use, would prefer and find most effective," Canadian Medical Association Journal, vol. 124, no. 5, pp. $563,1981$.

[7] J. L. Tangen, "Learning styles and supervision: A critical review," Clinical Supervisor, vol. 37, no. 2, pp. 241-256, 2017.

[8] C. Westby, "The myth of learning styles," Word of Mouth, vol. 31, no. 2, pp. 4-7, 2019.

[9] P. Kaushik, "Redefining learning: Kolb’s theory of learning styles with gardner's multiple intelligences," International Journal of Learning and Teaching, vol. 9, no. 1, pp. 330-339, 2017.

[10] S. Atar and I. Atar, "An invited commentary on "the socio-economic implications of the coronavirus and covid-19 pandemic: A review," International Journal of Surgery, vol. 78, no. 8, pp. 122, 2020.

[11] N. Donthu and A. Gustafsson, "Effects of COVID-19 on business and research," Journal of Business Research, vol. 117, no. 10, pp. 284-289, 2020.

[12] T. K. Burki, "Covid-19: Consequences for higher education," Lancet Oncology, vol. 21, no. 6, pp. 758, 2020.

[13] N. Iivari, S. Sharma and L. Ventä-Olkkonen, "Digital transformation of everyday life - how covid-19 pandemic transformed the basic education of the young generation and why information management research should care?," International Journal of Information Management, vol. 1, no. 55, pp. 102183, 2020.

[14] P. A. Federico, "Learning styles and student attitudes toward various aspects of network-based instruction," Computers in Human Behavior, vol. 16, no. 4, pp. 359-379, 2000.

[15] D. Keegan, "The two modes of distance education," Open Learning: The Journal of Open, Distance and E-Learning, vol. 13, no. 3, pp. 43-47, 1998.

[16] E. Şengel, "Effect of a web-based learning tool on student learning in science education: A case study [PDF]," 2005. [Online]. Available: academia.edu [Accessed: 27-Sep-2020]. 
[17] N. P. Morris, B. Swinnerton and T. Coop, "Lecture recordings to support learning: A contested space between students and teachers," Computers \& Education, vol. 140, no. 4, pp. 103604, 2019.

[18] J. Danielson, V. Preast, H. Bender and L. Hassall, "Is the effectiveness of lecture capture related to teaching approach or content type?," Computers \& Education, vol. 72, no. 6, pp. 121-131, 2014.

[19] I. E. Allen and J. Seaman, Making the Grade: Online Education in the United States, 2006. Needham, MA: Sloan Consortium, 2007.

[20] M. Khalifa and R. Lam, "Web-based learning: Effects on learning process and outcome," IEEE Transactions on Education, vol. 45, no. 4, pp. 350-356, 2002.

[21] V. Tinto, "Classrooms as communities: Exploring the educational character of student persistence," Journal of Higher Education, vol. 68, no. 6, pp. 599, 1997.

[22] I. Quitadamo and A. Brown, "Effective teaching styles and instructional design for online learning environments," ERIC, 2001. [Online]. Available: https://files.eric.ed.gov/fulltext/ED462942.pdf [Accessed: 27-Sep-2020].

[23] D. An and M. Carr, "Learning styles theory fails to explain learning and achievement: Recommendations for alternative approaches," Personality and Individual Differences, vol. 116, pp. 410-416, 2017.

[24] R. A. Rasheed, A. Kamsin and N. A. Abdullah, "Challenges in the online component of blended learning: A systematic review," Computers \& Education, vol. 144, no. 1, pp. 103701, 2020.

[25] A. P. Rovai, "Sense of community, perceived cognitive learning, and persistence in asynchronous learning networks," Internet and Higher Education, vol. 5, no. 4, pp. 319-332, 2002. 